\title{
Reinforcing Effects of Calcium Silicate-based Cement and Dual Cure Composite Resin in Simulated Immature Teeth with an Open Apex: An in vitro Study
}

\author{
${ }^{1}$ Murtuza S Zhabuawala, ${ }^{2}$ Roopa R Nadig, ${ }^{3}$ Veena S Pai, ${ }^{4}$ Yashwanth Gowda, ${ }^{5}$ Ranjini M Aswathanarayana
}

\begin{abstract}
Aim: To evaluate the fracture resistance of simulated immature teeth with an apical plug of biodentine followed by composite resin vs total obturation with biodentine tested immediately and after 3 months of aging and also to find out the chemical composition of dentin in contact with these materials.

Materials and methods: Extracted human maxillary central incisors with simulated immature apex with radicular dentin thickness (RDT) of 1 to $1.5 \mathrm{~mm}$ selected and divided into three groups of 20 each. Group I (control) - $4 \mathrm{~mm}$ biodentine apically and thermoplasticized gutta-percha. Group II-4 $\mathrm{mm}$ biodentine apically and composite resin. Group III-complete obturation with biodentine. About 10 samples from each group were tested immediately and remaining 10 stored in phosphate buffered solution (PBS) and tested after 3 months for fracture resistance and chemical analysis of dentin.
\end{abstract}

Results: No significant difference in fracture resistance between the groups was observed when tested immediately. After 3 months of aging, only biodentine group showed a significant reduction in fracture resistance with increased $\mathrm{Ca} / \mathrm{P}$ ratio of root dentine.

Conclusion: Biodentine group has shown drastic reduction in fracture resistance after 3 months of aging, and hence, cannot be recommended as a reinforcement material in immature teeth with thin dentin walls.

Keywords: Biodentine, Ca/P ratio, Dental trauma, Fracture resistance, Immature teeth, Paracore.

How to cite this article: Zhabuawala MS, Nadig RR, Pai VS, Gowda Y, Aswathanarayana RM. Reinforcing Effects of Calcium Silicate-based Cement and Dual Cure Composite Resin in Simulated Immature Teeth with an Open Apex: An in vitro Study. Int J Clin Pediatr Dent 2017;10(4):351-357.

Source of support: Nil

Conflict of interest: None

${ }^{1}$ Postgraduate Student, ${ }^{2}$ Professor and Head,,${ }^{3,5}$ Reader, ${ }^{4}$ Senior Lecturer

${ }^{1-5}$ Department of Conservative Dentistry and Endodontics Dayananda Sagar College of Dental Sciences, Bengaluru Karnataka, India

Corresponding Author: Murtuza S Zhabuawala, Postgraduate Student, Department of Conservative Dentistry and Endodontics Dayananda Sagar College of Dental Sciences, Bengaluru Karnataka, India, Phone: +919890360558, e-mail:murtuza_ dentist@yahoo.com

\section{INTRODUCTION}

Dental impact injuries are commonly associated with children between 8- and 12-years-old developing maxillary anterior teeth. ${ }^{1-3}$ These injuries often lead to pulpal necrosis leading to incomplete root development with an open apex, thin dentinal walls, and wide funnelshaped canal. ${ }^{4}$ Management of such cases is a significant challenge both endodontically and restoratively due to lack of adequate apical constriction and presence of thin dentinal walls. ${ }^{5}$ The traditional approach to the treatment of non-vital teeth with incompletely developed roots has been apexification using calcium hydroxide. ${ }^{4,6}$ Andreasen et $\mathrm{al}^{7}$ showed that immature roots which had calcium hydroxide placed within the root canals of immature teeth over 1 year had 50\% reduction in strength because of proteolytic reaction.

Revascularization has shown great potential for clinical success, although there is no established success rate for regenerative procedures. Garcia-Godoy and Murray ${ }^{8}$ stated that regenerative endodontic treatment is not recommended for patients younger than 7 years or older than 16 years.

Apical placement of mineral trioxide aggregate (MTA) and completion of a procedure in single appointment have been advocated as an promising alternative treatment option with high clinical success rate. ${ }^{9-11}$ Mineral trioxide aggregate has a good sealing ability, high degree of biocompatibility, low cytotoxicity, antimicrobial properties, ability to set in the presence of moisture, shorter treatment time, and induction of hard tissue deposition periradicularly. ${ }^{12}$ However, White et $\mathrm{al}^{13}$ reported that tooth strength is weakened after exposure to MTA for more than 5 weeks.

Recently, a new calcium silicate-based cement biodentine has been introduced which contains tricalcium silicate, calcium carbonate, and zirconium oxide and water-based liquid that has calcium chlorite and water reducing agent. It sets in 12 minutes and is recommended for use as dentine substitute. Similar to MTA, biodentine is biocompatible and when in contact with vital tissues it is said to be biologically active. The compressive strength and elasticity modulus are comparable with dentine and handling characteristics of biodentine is superior 
to MTA. ${ }^{14}$ Inspite of their favorable characteristics as an apical plug, the fragility of roots due to thin dentinal walls can compromise tooth strength, hence, reinforcement of radicular dentin is of utmost importance in such cases. ${ }^{15}$

Structural strengthening of non-vital immature teeth has received a great deal of attention and different materials and techniques have been examined. ${ }^{16-19}$ Composite resin has the ability to bond to root dentine walls, increasing the strength of the roots. However, it has certain disadvantages like polymerization shrinkage stresses, difficulty in complete curing, and increased c-factor in the root canal system. ${ }^{20}$ An alternative is the use of fiber post with an elastic modulus similar to dentine shown to have "Monoblock" effect. ${ }^{21,22}$ A mismatch between the diameter of post space and the fiber post is a problem, particularly in immature teeth with large root canals. ${ }^{23}$

Further, placing an apical plug of MTA or biodentine followed by placement of composite resin for radicular reinforcement has certain practical difficulties, such as many interfaces between the materials used, multiple treatment visits, removal of extra MTA/biodentine that has adhered to the root dentine may interfere with bonding and an attempt to remove the adhered material might result in unnecessary removal of already weakened radicular dentin. To overcome the above practical difficulties, there have been attempts to fill the entire canal with these materials. A study conducted to evaluate the fracture resistance of simulated immature teeth with biodentine apical plug and backfilling with various materials concluded that backfilling with guttapercha, fiber post, or biodentine does increase the force required to fracture immature teeth. ${ }^{24}$ However, in all of these above studies, testing was done immediately that too with canal wall thickness of $>2.5 \mathrm{~mm}$. Stuart et al ${ }^{25}$ suggested that the canal wall reinforcement of teeth with canal wall thickness of $2 \mathrm{~mm}$ or more may not be necessary. But most of the studies available in the literature has been done with the canal wall thickness of $2 \mathrm{~mm}$ or more. Therefore, evaluation of fracture resistance of rehabilitated teeth with canal wall thickness less than $1.5 \mathrm{~mm}$ is crucial and more relevant. Reinforcement of tooth root depends not only on the inherent strength of the obturating material but also on the quality of bond of the material with the root canal dentin and structural alteration that can happen in the material as well as root dentin over a period of time. Hence, this study is undertaken to evaluate the reinforcing effects of dual cure composite resin and biodentine on immature root dentin and also to find out if these materials can bring about any alteration in root canal dentin that can influence the tooth strength with time.

\section{MATERIALS AND METHODS}

Sixty extracted human maxillary central incisors measuring $5 \mathrm{~mm}$ faciolingually and $6 \mathrm{~mm}$ mesiodistally were selected for the study, disinfected with $5.2 \%$ sodium hypochlorite for 2 hours, and stored in distilled water until the beginning of the experiment. Preoperative radiographs were taken to rule out any aberrations in the anatomy. The roots of teeth were standardized to a length of $10 \mathrm{~mm}$ as measured from the apex to the facial cementoenamel junction (CEJ) by cutting the root tip to simulate incomplete root formation. Endodontic access cavities were made using round bur and Endo $\mathrm{Z}$ bur in a high speed hand piece and root canals were prepared using the Protaper rotary instruments. To achieve a simulation of teeth with immature apices, Peeso reamers between \#1 and \#6 were introduced into the root canal until \#6 pass freely out of the apex. After instrumenting with Peeso reamers, the radicular dentin thickness was $2.5 \mathrm{~mm}$. Further 703 carbide bur was used to obtain the remaining dentin thickness around $1.5 \mathrm{~mm}$ (Fig. 1). The samples were then subjected to cone beam computed tomography (CBCT) analysis to confirm the dentin thickness. The root canals were irrigated using $3 \mathrm{~mL}$ of 3\% sodium hypochlorite and final flush with $5 \mathrm{~mL}$ of $17 \%$ EDTA was carried out to remove smear layer. Biodentine mixed according to manufacturer's instruction was placed with a carrier and adapted using hand plugger in the $4 \mathrm{~mm}$ apical portion of the canal. The teeth were radiographed to verify correct position of the Biodentine. Samples were wrapped in wet gauze, placed in an incubator, and allowed to set for 12 minutes at $37^{\circ} \mathrm{C}$ with $100 \%$ humidity. Specimens were randomly divided into three groups with 20 specimens in each group.

Group I $(n=20)$ : AH Plus sealer was applied to the canal walls, backfilled with gutta-percha using Obtura II. Excess sealer was removed from the chamber with dry cotton pellet.

Group II $(n=20)$ : Dual-cured composite resin paracore was inserted into the canal and the excess resin was removed and light activation was performed for 40 seconds.

Group III $(n=20)$ : Biodentine was mixed and placed to a level just below the facial CEJ.

In all the groups after backfilling procedures, the access openings $2 \mathrm{~mm}$ below CEJ were filled with nanocomposite (Filtek Z35 0 XT; 3M ESPE, USA). Immediately after filling, 10 samples from each group were randomly divided into two subgroups. In subgroup A: specimens were stored for 1 week in PBS. In subgroup B: specimens were stored in PBS for 3 months until fracture resistance testing. Figure 1 shows radiographs of representative samples of the groups. 


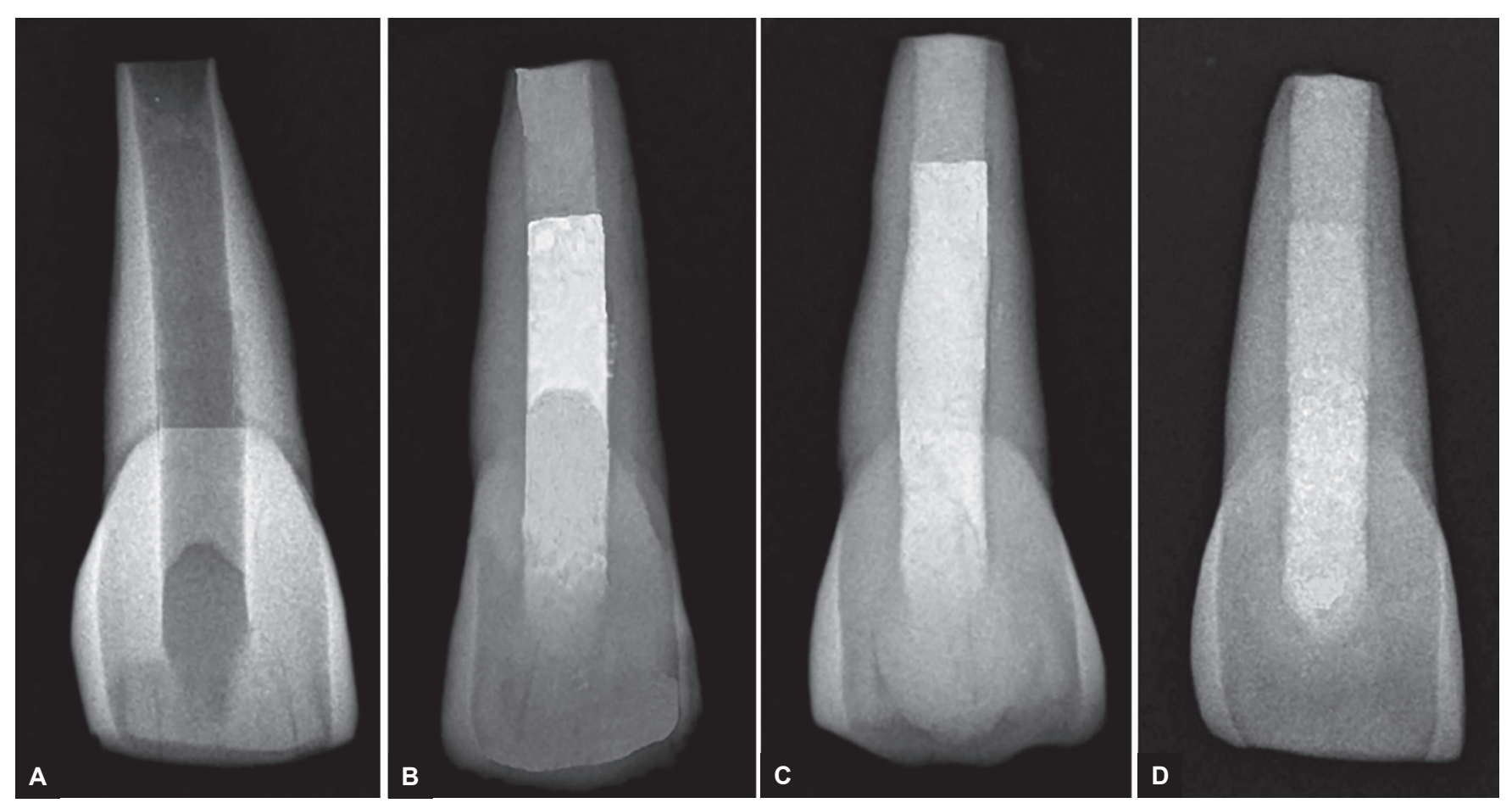

Figs 1A to D: (A) Simulation; (B) gutta-percha; $(C)$ paracore; and (D) biodentine

\section{Fracture Testing}

To simulate periodontal membrane, the root surfaces were coated with 0.2 to $0.3 \mathrm{~mm}$ thick layer of polyvinylsiloxane impression material and then embedded in the acrylic resin leaving the gap of $2 \mathrm{~mm}$ between the top of acrylic and to the CEJ. A custom-made jig was used to fix the cylinders at an angle of $45^{\circ}$ and a compressive load was applied from the palatal surface at crosshead speed of $1 \mathrm{~mm} /$ minute until fracture using universal testing machine. The maximum force required to fracture each specimens was recorded in Newtons. The data were statistically analyzed using one-way analysis of variance. The level of significance was set at $\mathrm{p}=0.05$.

\section{Energy Dispersive X-ray Analysis}

After testing fracture resistance, all the specimens were subjected to energy dispersive $x$-ray analysis to find out the chemical composition of the dentin. The root surfaces were split longitudinally with diamond disk and surfaces were etched with $37 \%$ phosphoric acid for 5 second and rinsed thoroughly with water and subjected to elemental analysis under high vacuum at 1,500 × magnification using energy dispersive system, which is attached to an environmental scanning electron microscope. The recorded values represented the average mineral weight percentage.

\section{RESULTS}

The mean values and their respective standard deviations of the force required to fracture the roots are presented in
Table 1: Mean fracture values for all groups measured in Newtons along with their standard deviations (immediate)

\begin{tabular}{lll}
\hline Groups & $n$ & $\begin{array}{l}\text { Mean forces }(n) \\
\text { standard deviation }\end{array}$ \\
\hline Backfilling with gutta-percha & 10 & $750.450 \pm 148.653$ \\
Backfilling with fiber post & 10 & $730.370 \pm 147.710$ \\
Backfilling with biodentine & 10 & $841.540 \pm 247.782$ \\
\hline
\end{tabular}

No significant differences $(p>0.05)$

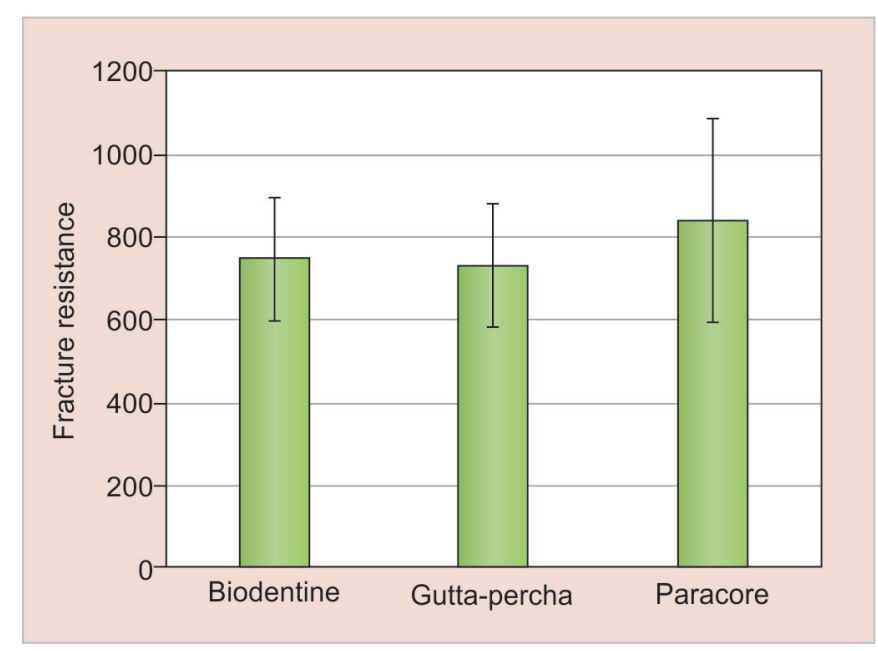

Graph 1: Comparison of fracture resistance between three groups immediately

(Table 1 and Graph 1) and (Table 2 and Graph 2). In immediate tested samples, higher mean fracture resistance was recorded in paracore group followed by Biodentine and gutta-percha group respectively. There was no statistical significant difference in mean fracture resistance between 
Table 2: Mean fracture values for all groups measured in Newtons along with their standard deviations (delayed)

\begin{tabular}{lll}
\hline Groups & $n$ & $\begin{array}{l}\text { Mean force }(n) \\
\text { standard deviation }\end{array}$ \\
\hline Backfilling with gutta-percha & 10 & $734.420 \pm 97.896$ \\
Backfilling with paracore & 10 & $787.680 \pm 116.578$ \\
Backfilling with biodentine & 10 & $612.160 \pm 63.799$ \\
\hline No significant differences $(p>0.05)$ &
\end{tabular}

the groups. In delayed tested samples, higher mean fracture resistance was recorded in paracore group followed by gutta-percha and Biodentine group respectively. The difference in mean fracture resistance was found to be significantly different between the groups $(p<0.01)$. On comparing immediate and delayed testing of Biodentine samples, the difference between them was found to be statistically significant $(p<0.001)$ where there was no significant difference in other two groups.

The mean values and their respective standard deviations of the $\mathrm{Ca} / \mathrm{P}$ ratio of dentin are presented in (Table 3 and Graph 3) and (Table 4 and Graph 4). In immediate

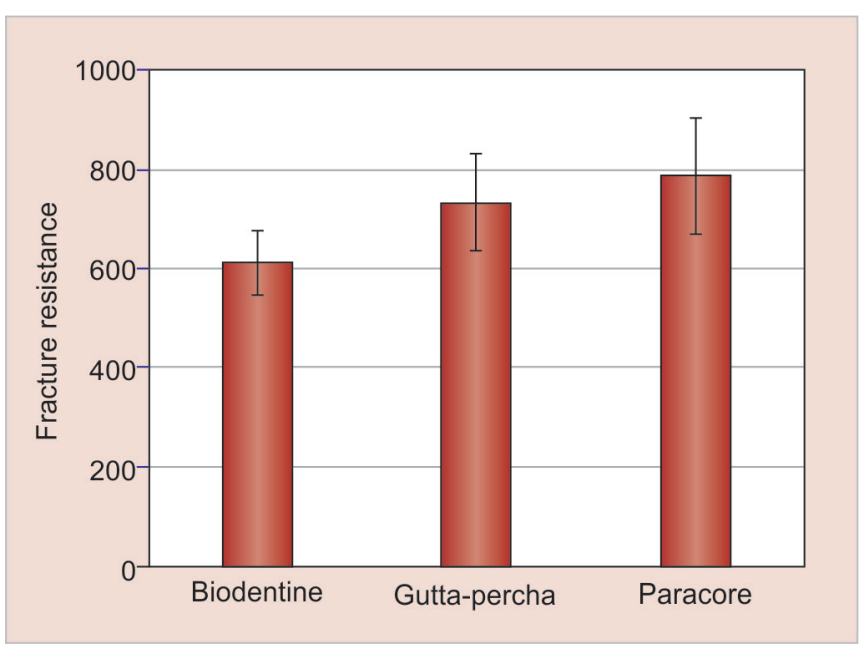

Graph 2: Comparison of fracture resistance between three groups after 3 months

tested samples higher mean $\mathrm{Ca} / \mathrm{P}$ ratio was recorded in biodentine group followed by paracore and gutta-percha group respectively. The difference in mean $\mathrm{Ca} / \mathrm{P}$ ratio among the groups was found to be statistically significant

Table 3: Mean $\mathrm{Ca} / \mathrm{P}$ ratio for all groups measured along with their standard deviations

\begin{tabular}{|c|c|c|c|c|c|c|c|}
\hline \multirow[b]{2}{*}{ Immediate } & \multirow[b]{2}{*}{ Mean } & \multirow{2}{*}{$\begin{array}{l}\text { Standard } \\
\text { deviation }\end{array}$} & \multirow[b]{2}{*}{ SE of mean } & \multicolumn{2}{|c|}{$95 \%$ Cl for mean } & \multirow[b]{2}{*}{ F-value } & \multirow[b]{2}{*}{$p$-value } \\
\hline & & & & Lower bound & Upper bound & & \\
\hline Biodentine & 2.33 & 0.12 & 0.04 & 2.25 & 2.41 & 6.216 & $0.006^{*}$ \\
\hline Paracore & 2.21 & 0.07 & 0.02 & 2.15 & 2.26 & & \\
\hline Gutta-percha & 2.17 & 0.13 & 0.04 & 2.07 & 2.26 & & \\
\hline
\end{tabular}

*Significant difference

Table 4: Comparison of $\mathrm{Ca} / \mathrm{P}$ ratio at delayed time interval among the three groups (ANOVA followed by Bonferroni multiple comparisons test)

\begin{tabular}{|c|c|c|c|c|c|c|c|}
\hline \multirow[b]{2}{*}{ Delayed } & \multirow[b]{2}{*}{ Mean } & \multirow{2}{*}{$\begin{array}{l}\text { Standard } \\
\text { deviation }\end{array}$} & \multirow[b]{2}{*}{ SE of mean } & \multicolumn{2}{|c|}{$95 \%$ Cl for mean } & \multirow[b]{2}{*}{$F$-value } & \multirow[b]{2}{*}{$p$-value } \\
\hline & & & & Lower bound & Upper bound & & \\
\hline Biodentine & 3.02 & 0.41 & 0.13 & 2.73 & 3.31 & 35.331 & $<0.001^{*}$ \\
\hline Paracore & 2.16 & 0.14 & 0.05 & 2.06 & 2.27 & & \\
\hline Gutta-percha & 2.18 & 0.12 & 0.04 & 2.09 & 2.27 & & \\
\hline
\end{tabular}

*Significant difference

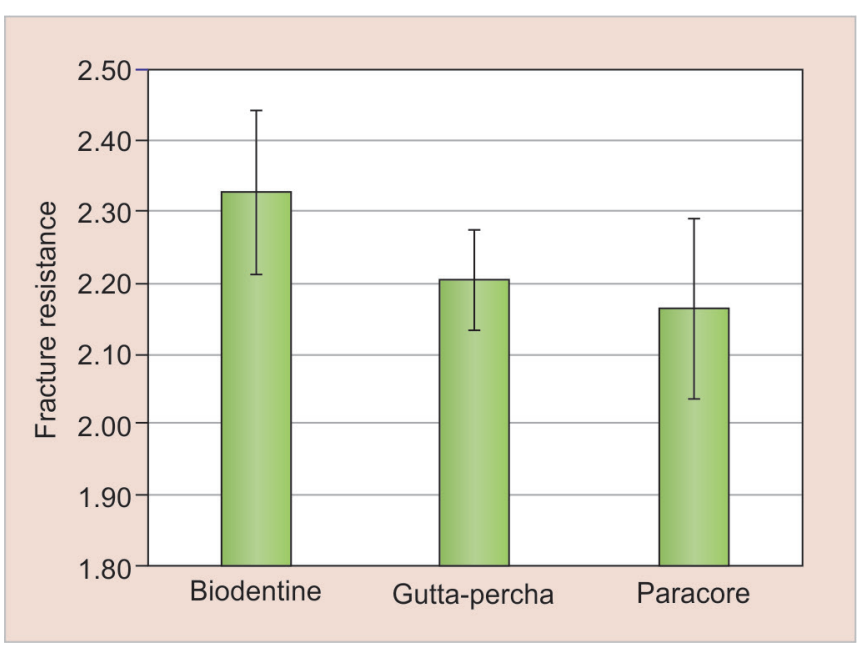

Graph 3: Comparison of $\mathrm{Ca} / \mathrm{P}$ ratio of dentin between three groups immediately

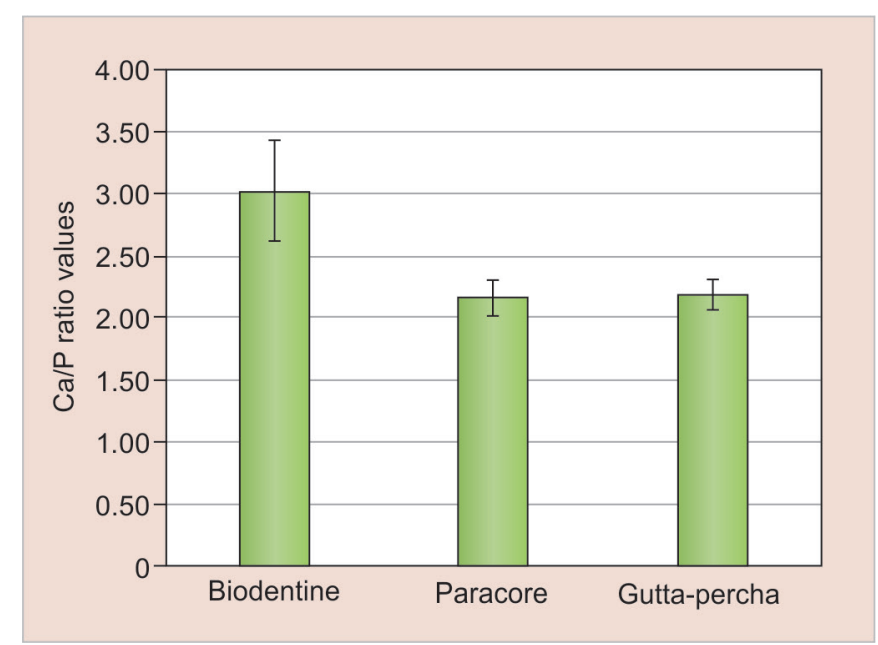

Graph 4: Comparison of $\mathrm{Ca} / \mathrm{P}$ ratio of dentin between three groups after 3 months 
( $\mathrm{p}<0.01$ ). In delayed tested samples higher mean $\mathrm{Ca} / \mathrm{P}$ ratio was recorded in biodentine group followed by guttapercha and paracore group respectively. The difference in mean $\mathrm{Ca} / \mathrm{P}$ ratio among the groups was found to be statistically significant $(\mathrm{p}<0.001)$. On comparing immediate and delayed testing of biodentine samples, higher mean $\mathrm{Ca} / \mathrm{P}$ ratio was recorded in the delayed specimens compared with immediate specimens and the difference between them was found to be statistically significant $(p<0.001)$ where there was no significant difference in other two groups.

\section{DISCUSSION}

Reinforcement of endodontically treated immature teeth assumes great importance as these teeth are more susceptible to external and masticatory forces. The selected material for reinforcement must be applied easily in clinical practice, bond successfully to dentine, and serve as a good barrier against microleakage. ${ }^{25}$ Reinforcing capability of biodentine was evaluated in this study because in addition to being bioactive and biocompatible material, it has improved handling characteristics and less time consuming than MTA. Han and Okiji ${ }^{26}$ suggested that BD may have a remarkable biomineralization capability than MTA.

In most of the studies, found in the literature, to simulate immature teeth, the canals were instrumented with Peeso reamers (1-6) until a size 6 Peeso can be passed $1 \mathrm{~mm}$ beyond the apex to simulate open apex, this would only result in dentin thickness of 2 to $2.5 \mathrm{~mm}$. Investigations have revealed that the reinforcement of a canal with a diameter less than $1.5 \mathrm{~mm}$ is not necessary while wall thickness of $2.63 \mathrm{~mm}$ is insufficient to weaken tooth structure. ${ }^{25}$ Therefore, preparation of the canal was further enlarged with 702 carbide burs to approximate Cvek's stage 3 root development. Cvek's stage 3 root development was selected for the present model; because at this stage, the root-to-canal ratio in a mesiodistal dimension at the CEJ is nearly $1: 1{ }^{15,27}$ In the present study, after the simulation of all the samples, CBCT was used to find out the accurate thickness of the remaining radicular dentin.

While testing for fracture resistance, the load was applied at an angle of $45^{\circ}$ to the long axis of the tooth to simulate the average angle of contact between maxillary and mandibular incisors in a class I occlusion. ${ }^{24,25}$ On evaluating the results, in immediate tested specimens, teeth restored with paracore group showed the highest fracture resistance followed by biodentine and then gutta-percha. However, there was no statistical significant difference between the groups tested in the study. A preliminary study by Yasir ${ }^{28}$ evaluated the fracture resistance between biodentine and gutta-percha in immature teeth and reported that there was no statistical significant difference between groups. A similar study by Topçuoğlu et $\mathrm{al}^{24}$ evaluated the fracture resistance between biodentine, gutta-percha, and fiber post group in immature teeth and suggested that there is no significant difference between biodentine and gutta-percha group. In the present study, access composite is extended $2 \mathrm{~mm}$ apical to $\mathrm{CEJ}$ to provide an additional root strength necessary to minimize cervical root fracture. Seto et $\mathrm{al}^{29}$ reported that composite resin to a depth of $3 \mathrm{~mm}$ would significantly strengthen the roots in immature teeth. So this could be one possible reason, why there was no statistical significant difference in the fracture strength between the control group and the experimental groups in the current study.

After 3 months of storage, teeth restored with paracore have shown the highest fracture resistance followed by gutta-percha and biodentine showed the least fracture resistance. The difference between immediate and delayed paracore groups, there was a reduction in fracture resistance although it was not statistical significant. Tay et $\mathrm{al}^{30}$ reported that the degradation patterns of resindentin interface inside the root canal created by selfetching adhesive systems due to water sorption and induced collagenolytic activity adversely affects the longevity of adhesively bonded post. Tay and Pashley ${ }^{31}$ reported that the self-etching systems due to their hydrophilic characteristics tend to present potential degradation in the course of time, as water plays a key role in polymer degradation and concluded that the tested etch-and-rinse adhesive systems had a better performance in terms of bond durability over time than the self-etching adhesive systems and thus monoblock effect is questionable over a period of time. However, our study was of 3 months duration and the longevity of the bond with extended time periods needs further evaluation. The difference between immediate and delayed biodentine group, there is a drastic reduction in the tooth strength after 3 months of storage. Bowes ${ }^{32}$ and Leiendecker et $\mathrm{al}^{33}$ reported that highly alkaline calcium hydroxide induces a caustic degradation effect on exposed collagen and this is mediated by the breakdown of intermolecular bonds in collagen fibrils, increasing their water absorption leading to swelling. A recent study by Sawyer et $\mathrm{al}^{34}$ reported that dentin flexural strength for dentin exposed to biodentine and MTA decreased significantly after 2 and 3 months. Atmeh et $\mathrm{al}^{35}$ examined the dentin cement interfacial interaction with biodentine and reported that in confocal images a layer of mineral infiltration zone is associated with an altered intertubular microstructure leading to change in optical properties of interfacial dentin. SEM micrographs showed the same band of structurally altered dentin immediately beneath the biodentine 
which is due to high alkalinity of hydrated biodentine, which has induced a caustic denaturing and permeability of organic collagen component of interfacial dentin. Therefore, it is possible that the above reaction might have lead to decreased tooth strength of the biodentine samples after 3 months. Another reason for the decreased tooth strength with biodentine after 3 months of aging could be the solubility of biodentine. Singh et $\mathrm{al}^{36}$ have reported that the solubility of biodentine after 30 days and 60 days immersion period was significantly higher as compared with MTA. Vivan et $\mathrm{a}^{37}$ theorized that a material releasing calcium ions to exert biologic effect to some extent solubilize and dissociate from fully hardened cement thus resulting in disintegration. In the present study, radiographic examination of the samples observed showed reduction in the radioopacity of biodentine after 3 months of aging which could suggest the disintegration of this material over a period of time. Hence, further evaluation is required for biodentine to be used in apexification procedure. In the present study, radicular dentin of biodentine group has shown a significant increase in the $\mathrm{Ca} / \mathrm{P}$ ratios from the mean value of 2.33 to 3.02 , thus connoting a gain in the mineral content. Thus, these results are in accordance with the previous mentioned study by Han and Okiji ${ }^{26}$ who stated that both biodentine and MTA caused the uptake of $\mathrm{Ca}$ and $\mathrm{Si}$ in the adjacent root canal dentine in the presence of PBS who reported that Ca and Si uptake in dentin areas. The dentin element uptake was more prominent for biodentine than MTA. Therefore, in the present study, solubility of biodentine could be due to higher uptake of ions by the root canal dentin, which could have altered the physical properties of biodentine and therefore, strength of biodentine itself is reduced over a period of time. It is interesting to note that HatibovicKofman et a ${ }^{38}$ compared the influence of MTA and CH on fracture resistance in sheep teeth and stated that over 1 year period, MTA and $\mathrm{CH}$ have showed a $2 \%$ and $26 \%$ decrease in fracture resistance. Authors reported that after initial decrease in the fracture resistance of MTA treated teeth, the process is reversed, and fracture resistance increases for a period between 2 months and 1 year. It can be explained by the fact that MTA induces the expression of TIMP-2 in dentin matrix and suppress the degenerative activities of MMP-2 and - 14 . Whether similar phenomenon can be observed in biodentine needs further evaluation.

\section{CONCLUSION}

There was no statistically significant difference in the fracture resistance of an immature tooth with an apical plug of biodentine followed by obturation with guttapercha, paracore, or biodentine. After 3 months of aging, biodentine group has shown a drastic reduction in the fracture resistance whereas there is no significant reduction in gutta-percha and paracore groups. EDX analysis shows increased $\mathrm{Ca} / \mathrm{P}$ ratio of root canal dentin of biodentine group compared to gutta-percha and paracore after 3 months of aging, whether this uptake of minerals is responsible for decreased tooth strength needs further evaluation. Therefore, biodentine cannot be recommended as a reinforcement material in immature teeth with thin dentinal walls. Further in vitro and in vivo investigations are necessary to validate the above findings.

\section{CLINICAL SIGNIFICANCE}

- Dental impact injuries involve children at school age between 8 and 12 years can lead to pulpal necrosis with incomplete root formation.

- Management of such cases is a significant challenge endodontically as well as restoratively.

- Structural strengthening of immature teeth has received a great deal of attention and therefore, different materials and techniques have been examined.

\section{REFERENCES}

1. Araujo MA, Valera MC. TratamentoClinico dos Traumatismos Dentarios. Sao Paulo: ArtesMedicas; 1999. p. 277.

2. Andreasen JO, Andreasen FM, Backland LK, Flores MT. Traumatic dental injuries, a manual. 2nd ed. Vol. 9. Oxford: Blackwell Munksgaard; 2003. p. 58-60.

3. Ravnn JJ. Dental injuries in Copenhagen school children, school years 1967-1972. Community Dent Oral Epidemiol 1974;2(5):231-245.

4. Rafter M. Apexification: a review. Dent Traumatol 2005 Feb;21(1):1-8.

5. Mente J, Hage N, Pfefferde T, Koch MJ, Dreyhaupt J, Staehle HJ, Friedman S. Mineral trioxide aggregate apical plugs in teeth with open apical foramen: a retrospective analysis of treatment outcome. J Endod 2009 Oct;35(10):1354-1358.

6. Dominguez Reyes A, Muñoz Muñoz L, Aznar Martin T. Study of calcium hydroxide apexification in 26 young permanent incisors. Dent Traumatol 2005 Jun;21(3):141-145.

7. Andreasen JO, Farik B, Munksgaard EC. Long term calcium hydroxide as a root canal dressing may increase risk of root fracture. Dent Traumatol 2002 Jun;18(3):134-137.

8. Garcia-Godoy F, Murray PE. Recommendations for using regenerative endodontic procedures in permanent immature traumatized teeth. Dent Traumatol 2012 Feb;28(1):33-41.

9. Moroto M, Barberia E, Planells P, Vera V. Treatment of non vital immature incisor with mineral trioxide aggregate. Dent Traumatol 2003 Jun;19(3):165-169.

10. Bramente CM, Menezes R, Moraes IG, Garcia RB. Use of MTA and intracanal post reinforcement in a horizontally fracture tooth: a case report. Dent Traumatol 2006 Oct;22(5):275-278.

11. Oliveira TM, Sakai VT, Silva TC, Santos CI. MTA as an alternative treatment for intruded permanent teeth with root resorption and incomplete apex formation. Dent Traumatol 2008 Oct;24(5):565-568.

12. Torabinejad M, Parirokh M. Mineral Trioxide Aggregate: a comprehensive literature review - part II: leakage and biocompatibility investigations. J Endod 2010 Feb;36(2):190-202. 
13. White JD, Lacefield WK, Chavers LS. The effect of three commonly used endodontic materials on the strength and hardness of root dentin. J Endod 2002 Dec;28(12):828-830.

14. Biodentine (Active biosilicate technology) a scientific file by Septodont. Available from: www.ndd.no/biodentine/scientific file.

15. Tanalp J, Dikbas I, Malkondu O, Ersev H, Güngör T, Bayırlı G. Comparison of the fracture resistance of simulated immature permanent teeth using various canal filling materials and fiber posts. Dent Traumatol 2012Dec;28(6):457-464.

16. Cauwels RG, Pieters IY, Martens LC, Verbeeck RM. Fracture resistance and reinforcement of immature roots with guttapercha, MTA and calcium phosphate bone cement: a standardized in vitro model. Dent Traumatol 2010 Apr;26(2):137-142.

17. Wilkinson KL, Beeson TJ, Kirkpatrick TC. Fracture resistance of simulated immature teeth filled with resilon, guttapercha or composite. J Endod 2007 Apr;33(4):480-483.

18. Hemalatha H, Sandeep M, Kulkarni S, Yakub SS. Evaluation of fracture resistance in simulated immature teeth using resilon and ribbond as root reinforcements - an in vitro study. Dent Traumatol 2009 Aug;25(4):433-438.

19. Goldberg F, Kaplan A, Roitman M, Picca M. Reinforcing effect of a resin glass ionomer in the restoration of immature roots in vitro. Dent Traumatol 2002 Apr;18(2):70-72.

20. Tay FR, Loushine RJ, Lambrechte P, Weller RN, Pashley DH. Geometric factors affecting dentin bonding in root canals: a theorotical modeling approach. J Endod 2005 Aug;31(8):584-589.

21. Bortoluzzi EA, Sauza EM, Reis JM. Fracture strength of bovine incisors after intraradicular treatment with MTA in an experimental immature tooth model. Int Endod J 2007 Sep;40(9):684-691.

22. Soares CJ, Santana FR, Castro CG, Santos-Filho PC, Soares PV, Qian F, Armstrong SR. FEM and bond strength of glass post to intraradicular dentin: comparison between microtensile and push out tests. Dent Mater 2008 Oct;24(10):1405-1411.

23. Brito-Júnior M, Pereira RD, Veríssimo C, Soares CJ, Faria-eSilva AL, Camilo CC, Sousa-Neto MD. Fracture resistance and stress distribution of simulated immature teeth after apexification with MTA. Int Endod J 2014 Oct;47(10):958-966.

24. Topçuoğlu HS, Kesim B, Düzgün S, Tuncay Ö, Demirbuga S, Topçuoğlu $G$. The effect of various backfilling techniques on the fracture resistance of simulated immature teeth performed apical plug with Biodentine. Int J Paediatric Dent 2015 Jul;25(4):248-254.

25. Stuart $\mathrm{CH}$, Schwartz SA, Beeson TJ. Reinforcement of immature roots with a new resin filling material. J Endod 2006 Apr;32(4):350-353.
26. Han L, Okiji T. Update of calcium and silicon released from calcium silicate based materials into root canal dentine. Int Endod J 2011 Dec;44(12):1081-1087.

27. Desai S, Chandler N. The restoration of permanent immature anterior teeth, root filled using MTA: a review. J Dent 2009 Sep;37(9):652-657.

28. Yasir OB. Biodentine as root filling material in immature permanent teeth - a preliminary an in vitro study. King's College London;2012. Available from: www.asnarportan.com/files/ thesis YOB.

29. Seto B, Chung KH, Johnson J, Paranjpe A. Fracture resistance of simulated immature maxillary anterior teeth restored with fiber posts and composite to varying depths. Dent Traumatol 2013 Oct;29(5):394-398.

30. Tay FR, Pashley DH, Loushine RJ, Weller RN, Monticelli F, Osorio R. Self-etching adhesives increase collagenolytic activity in radicular dentin. J Endod 2006 Sep;32(9):862-868.

31. Tay FR, Pashley DH. Water treeing - a potential mechanism for degradation of dental adhesives. Am J Dent 2003 Feb;16(1): 6-12.

32. Bowes J. The swelling of collagen in alkaline solutions; swelling in solutions of bivalent bases. Biochem J 1950 May;46(5):530-532.

33. Leiendecker AP, Qi YP, Sawyer AN, Niu LN, Agee KA, Loushine RJ, Weller RN, Pashley DH, Tay FR. Effects of calcium silicate based materials on collagen matrix integrity of mineralized dentin. J Endod 2012 Jun;38(6):829-833.

34. Sawyer AN, Nikonov SY, Pancio AK, Niu LN, Agee KA, Loushine RJ, Weller RN, Pashley DH, Tay FR. Effects of calcium silicate based materials on the flexural properties of dentin. J Endod 2012 May;38(5):680-683.

35. Atmeh AR, Chong EZ, Richard G, Festy F, Watson TF. Dentincement interfacial interaction: calcium silicates and polyalkenoates. J Dent Res 2012 May;91(5):454-459.

36. Singh S, Podar R, Dadu S, Kulkarni G, Purba R. Solubility of a new calcium silicate based root end filling material. J Conserv Dent 2015 Mar-Apr;18(2):149-153.

37. Vivan RR, Zapata RO, Zeferino MA, Bramante CM, Bernardineli N, Garcia RB, Hungaro Duarte MA, TanomaruFilho M, Gomes de Moraes I. Evaluation of the physical and chemical properties of two commercial and three experimental root end filling materials. Oral Surg Oral Med Oral Pathol Oral Radiol Endod 2010 Aug;110(2):250-256.

38. Hatibovic-Kofman S, Raimundo L, Zheng L, Chong L, Freidman M. Fracture resistance and histological findings of immature teeth treated with mineral trioxide aggregate. Dent Traumatol 2008 Jun;24(3):272-276. 